\title{
A qualitative study of mentoring and career progression among junior medical doctors
}

\author{
Rosaline 0. Garr ${ }^{1}$, Philip Dewe ${ }^{2}$ \\ ${ }^{1}$ Department of Paediatrics, St Helens \& Knowsley Teaching Hospitals, Merseyside, UK \\ ${ }^{2}$ Department of Organisational Psychology, Birkbeck University of London, UK
}

Correspondence: Rosaline O. Garr, Consultant Paediatrician, St Helens and Knowsley Teaching Hospitals, Whiston hospital, Prescot, Merseyside. L35 5DR, UK. E-mail: rgarr@doctors.org.uk

\begin{abstract}
Objectives: To explore the perceptions of mentees of the role mentoring plays in developing a medical career and seeming advantages and disadvantages.

Methods: In this qualitative study, 21 mentored and nonmentored doctors in postgraduate specialty years one to eight were recruited from the Mersey deanery in England. Semi-structured interviews were used to assess perceptions of the mentored postgraduate trainees (mentees) and views of the non-mentored trainees. The interview transcripts were thematised using thematic analysis methods.

Results: Themes of how mentoring was understood by trainees were; a supportive relationship by someone senior providing advice and guidance and informal adviser relating to training and personal issues. Advantages included, someone who was approachable, trustworthy and empathetic who gave a wider and different perspective.
\end{abstract}

Difficulty with mentoring occurred when confidentiality was broken as this potentially affected work/colleagues relationship. Lack of knowledge of what mentoring was, and obtaining a mentor were barriers. Facilitators included having identified peer mentoring facilitators, networking and ability to choose a mentor.

Conclusions: This study showed that mentoring was valued by postgraduate doctors in training, those who were mentored found mentoring to be important to their personal and professional development. Training for the mentor and mentee would help to manage expectations and ensure effective mentoring. Allocating a mentor to all trainees may normalise the concept of mentoring. A mentor should not be an assessor to their mentee as it raises issues of conflict of interest.

Keywords: Mentors, physicians junior, education, supervision

\section{Introduction}

Mentoring is an old concept but the value to organisations has only been acknowledged in the last 20 years. ${ }^{1}$ Coaching tends to be used interchangeably with mentoring hence they are often referred to as developmental relationships. ${ }^{2}$ Generally, mentoring is understood as a positive developmental opportunity ranging from need for a directive to a less directive approach depending on the needs of the trainee. The importance of mentoring as a tool in fostering career development in all areas of the medical profession, including non-technical skills is increasingly being recognised. ${ }^{3,4}$ Indeed in a Harvard business review article mentoring is thought to be essential for leadership development. ${ }^{5}$ Mentoring theory suggests that effective mentoring should enhance career prospects. ${ }^{6}$ Mentors can inspire trainees, fostering idealism and humanness in medicine ${ }^{7}$ although a connection needs to be established between the mentor and mentee for an effective mentoring relationship. Nonmentored individuals report significantly less job satisfaction, organisational commitment and procedural justice. ${ }^{8}$ Mentoring is noted to be even more vital during periods of change, however there is still more to learn about how it is perceived and what goes on in the mentoring relationship. ${ }^{9}$ When mentoring goes wrong the mentee is usually portrayed as the victim, at the mercy of the more powerful mentor. ${ }^{10} \mathrm{~A}$ mentor who has a direct supervisory role to the mentee would lead to a poor relationship, as the role of a mentor may be in direct conflict to the supervisory role. ${ }^{11}$ Ensuring that the human aspect of medicine is not trained out of the doctors suggests a need for attention to be given to the psychosocial as well as the career elements of training 
and that is what mentoring does. ${ }^{12}$ Empathy which is related to emotional intelligence is fostered by mentoring and this will ultimately make a big difference to patient care. Mentoring and coaching are now well established in industry and are increasingly being advocated in medicine, another reason why it is important to understand its role as a developmental tool. Mentoring is available to some postgraduate training doctors in the Mersey deanery and some hospitals also provide mentoring opportunities. This study aims to evaluate the role mentoring plays in developing a medical career and seeming advantages and disadvantages from the perspective of the postgraduate training doctors who were mentored (mentees) and the postgraduate training doctors who were not mentored (trainees). The term trainee is also used when referring to views from all the postgraduate training doctors whether mentored or nonmentored. Career progression here is as defined by the trainee.

\section{Methods}

\section{Participants}

Trainees were approached after a request was made via the deanery. An e-mail, mail shot was then sent to the trainees by the deanery, requesting those who would like to participate in the study to respond. The e-mails of those interested in the study were then forwarded to one of the authors. They were then contacted and written information about the study was sent to the participants. They were asked to consent to the study if they were still interested. Those who consented were given the option of a telephone or face to face interview at a venue of their choice. The instrument used (see appendix) was a modified version of a template in a previous study. ${ }^{13}$ There were no preconceived ideas, as the study was designed in a qualitative manner for themes to be identified. This method was used as an ideal way to capture the trainees' views without the constraints of prescribed answers or poor response rate from a questionnaire survey. As a result, this study was seen as exploratory representing a first step in understanding the role mentoring plays in developing a medical career. Ethics committee approval was obtained from the Department of Organizational Psychology at Birkbeck, University of London as well as permission from the Deanery to interview the trainees. Consent from each participant was also obtained. Information explaining how the data would be anonymous and used for a Masters project, as well as publication was given to each participant before consent was sought. They also had the option of not continuing with the interview at any stage if they changed their mind.

Interviews were conducted with 21 training doctors from different health organisations in a geographical region, Mersey training deanery. There were 12 male and 9 female trainees. The majority were in the 30-39 age brackets, trainees were between specialty training (ST) one and eight, with nine above ST4. The majority of participants obtained their primary medical qualification in the United Kingdom. Trainees were from a number of specialties in medicine; hospital and general practice, but can broadly be categorised as 17 medical and 4 surgical trainees. Twelve of the trainees had a mentor, so were mentees and 9 were non mentored.

\section{Interview procedure}

The first 21 trainees who consented to the study had semistructured interviews. The interviews were conducted by phone for 13 trainees and face to face for 8 . The interviews were audio taped and transcribed verbatim. Each interview lasted from a minimum of 10 minutes to a maximum of 26 minutes. The recorded interviews were deleted after transcription.

Thematic analyses methods were used to draw out the themes from the mentees. ${ }^{14,15}$ The responses were assigned numbers for anonymity. The knowledge, experiences and evaluations regarding mentoring by the trainees were explored. The responses to each question, by all the trainees were grouped together. The responses to the questions that were specific to the mentored and non-mentored trainees were grouped as such. The recurring themes were found and identified.

\section{Results}

\section{Interviews with trainees}

\section{The definition of mentoring by trainees}

In response to what mentoring is, all the trainees were clear about what mentoring is with four main themes identified; a senior person whom you can rely on for advice and guidance, someone providing support, an informal adviser relating to training and personal issues to help and develop and a supportive relationship with someone not directly related to your work. These are summed up in these quotes.

\footnotetext{
"It's a relationship where someone with more experience or skill in an area helps another." (Mentee, No 21, female)

"To me its someone that is an expert in their field who can provide guidance with non-clinical stuff like how to develop critical thinking skills, develop your career, overseeing career some of it by example." (Mentee, No 5, male)
}

\footnotetext{
"A person who is easily approachable and with whom I can talk but who is not directly related with my work, not my supervisor or tutor, a third person with whom I can easily approach and talk and discuss if I have a problem" (Non mentored trainee, No 20, female)
}

"I think mentoring probably is a form of guidance, for in the context of training I suppose for a trainee, from someone who is professionally qualified to provide advice and career advice but who is sufficiently detached from that trainee's formal training if you like. I think it is like an informal adviser the trainee can speak to about issues relating to training, personal issues as well, a kind of a confidant, but I think in my mind a mentor is someone who is not intimately related to the formal educational 
supervisors, supervisor consultant and dean etc. of that trainees programme. So that they can probably feel a bit more free to talk about worries and things." (Non mentored trainee, No 2, male)

\section{Advantages and disadvantages of mentoring and relation to training}

What is good about the mentoring relationship or having a mentor? Having someone who is approachable, supportive, honest and trustworthy, flexible, always responds to queries, gives a wider and different perspective; empathetic, feeling of not being alone, role model and an opportunity for reflection, confidentiality during enquiry about issues and network of support.

\begin{abstract}
"It was flexible, that the advice is specific to which ever point you are at in your career rather than generic advice, because you can get generic advice on the website, the mentor is someone who knows you and knows your background and can be supportive because they know where you are coming from." (Mentee, No 6, female)

"Its not only having somebody who can support you but also who might have a wider and different perspective, might be able to help with personal and professional life situations you encounter at work." (Non mentored trainee, No 14, male)
\end{abstract}

\section{Should mentoring be an important part of training?}

Overwhelmingly, yes, both the mentored and nonmentored trainees stated that mentoring should be an important part of training. It should be available to all not only when there is a problem, but also as an additional level of guidance and pastoral care. Trainees think mentors should be trained and the mentoring process must be separate from assessment procedures.

\footnotetext{
"Yes, I believe that mentorship should be a part of training, every trainee is individually different from the other trainee and they have specific issues, mentor could be a guide who can provide ideas about how to accomplish, otherwise we are just beating around the bushes." (Mentored trainee, No 10, male)

"I think it should be, so far the structures are educational supervisors, clinical supervisors, dean but I think the mentor is an additional level of guidance and pastoral care if you want to put it that way. I think that will be good, very useful actually." (Non-mentored trainee, No 2, male)
}

Mentored and non-mentored trainees think that mentors look at the overall development of the trainee as a clinician, especially at vulnerable times like the foundation years, training gaps, examinations or transition periods. They stated that it should be an informal arrangement separate from the educational supervisor; everyone should have access to a trained mentor whom the mentee has chosen. Trainees should also have training on what mentoring is and that peer mentoring should be considered.

Peer mentoring refers to a trainee one or two years ahead mentoring a more junior colleague especially for issues like the electronic portfolio. They stated that this would promote a supportive environment and reduce sickness absence. They said that mentors could be a confidante, could give a wider perspective, help identify strengths of trainees and also teach practical skills.

\footnotetext{
"I think it is very good to have a mentor. I think somebody that is just a year ahead of you is very good to say look don't worry about this it is completely normal and everything will be fine." (Non-mentored trainee, No 3, female)
}
".....educational supervisors focus on the curriculum I don't see them as mentors. Mentors look at the overall development of the clinician and relationship over a long period of time." (Mentee, No 5, male)

All non-mentored trainees think it is a good thing to have a mentor. The mentored trainees said it had positive impact on their careers as it gave a wider perspective a trainee said

$$
\text { “...opened my eyes to possibilities.” (Mentee, No 6, female) }
$$

There is career guidance, problem solving, how to approach situations, achieving goals, identifying what needs to be done as well as collaborative projects. The mentors provide a sounding board, confidence, constructive, impartial advice, emotional and moral support.

\section{"I think so yes" (Non-mentored trainee, No 14, male)}

"It opened my eyes to the possibilities of getting that training elsewhere." (Mentee, No 6, female)

\section{Regarding what may be bad about mentoring}

The non-mentored trainees said there was nothing bad, if it worked but if there was a clash with the mentor, if confidentiality was broken, it could affect work/colleagues relationship. This was another reason why the mentor should not be the educational supervisor. The mentored trainees stated that mentoring had not hindered their career but said that not having a mentor was a hindrance. Some negative aspects were mentors who imposed their advice, rather than enabling the trainee to make up their own mind, a trainee said:

$$
\begin{aligned}
& \text { "mentors should know what they should and shouldn't do." } \\
& \text { (Mentee, No 10, male) }
\end{aligned}
$$

It was felt that dependency on the mentor could be a problem therefore limiting options. Mentees should also know what they want from the process.

\footnotetext{
"The one thing I can imagine is that, its important to find the right mentor and I think its important that you know what you want from a mentor before you go to them but personally, I've got no problems." (Mentee, No 18, male)
} 
"If there was an issue at work and it is related to the mentor, you might not be able to use the mentor, may need someone else, you don't always get on with your mentor." (Non- mentored trainee, No 16, female)

\section{Qualities of a good mentor}

Characteristics that make a good mentor: This was similar across the mentored and non-mentored trainees including; a good listener, warm, welcoming, patient, nonjudgemental, and empathetic. Honest, open minded, trustworthy, caring these are personal qualities. Mentors are required to be approachable, available and have an interest in developing the mentees' career. Being of good standing, expert and knowledgeable especially in academic disciplines are important. There was a requirement to know limitations and sign post as necessary. The mentor is seen as a role model someone to aspire to, but also someone who gives direction and guidance.

\footnotetext{
"Someone who is open minded, empathetic and caring and someone who takes a holistic approach to trainee, someone who is quite organised as well." (Mentee, No 8, female)

"I think they have to be approachable, be a good listener, also practical. Ideally a mentor is somebody who can practically help you reach your goals. So they have got to have realistic solutions or ideas about how you are going to achieve your goals. Also be honest if they think your goals aren't achievable or a little bit unrealistic at that stage and help you get to that realisation without making you feel bad I suppose." (Non-mentored trainee, No 15, female)
}

\section{Discussion}

\section{How mentoring is understood by trainees}

Mentoring is understood in slightly different ways by the trainees, but thematic analysis showed some consensus, trainees' understanding of mentoring is as stated in the medical literature. ${ }^{16}$ Mentoring is conducted in the context of a supportive, non-judgemental and confidential relationship. An additional but important point from the mentees perspective is that the mentor is someone not directly related to their work. The main reason given for the use of mentoring that related to most trainees is the benefit of intuitive learning which cannot be obtained from a book. ${ }^{17}$ The trainees state that it is a process that should be proactively offered from the onset, at the foundation stage upwards to enable good, tailored choices to be made. The first educational supervisors meeting would be an opportunity to introduce the concept of mentoring and mentors, as a separate resource from the educational supervisor. A proactive approach to mentoring reduces isolation and develops latent potential as well as ensuring awareness for all, of the benefits of mentoring; reducing the 'stigma' attached to mentoring in medicine. The concept of the good mentor, bad mentor and good enough mentor has been reviewed ${ }^{18}$ this showed that a bad mentor in a dysfunctional relationship with a mentee caused more harm. Pastoral care is more likely in informal relationships of four years. Majority of trainees in this study have more than one mentor, perhaps reflecting the complex needs of trainees in medicine. The issues of confidentiality and trust are frequently mentioned. These are core to establishing effective relationships. Some participants mentioned that in some cases formal mentoring relationship contracts are signed. ${ }^{18}$

\section{Mentor motivation and trainees career development}

When mentors are motivated by the care of the mentee, confidentiality would not be an issue. A study showed that when mentors and mentees were from the same department there were more negative job and career attitudes than when they were from different departments. ${ }^{18}$ This perhaps could be due to information learned in the mentoring session impacting negatively in the work place, strengthening the notion that mentoring and educational supervision should be kept as separate activities. An opposing view noted that mentors that are internal to the organisation appear to satisfy mentees needs better than mentors who are in other organisational contexts. ${ }^{8}$ Being in the same field may increase awareness of the potential situations and stresses the mentees might face. Tacit learning would also be more effective, and they can help the mentees realise their hidden talents.

The European mentoring and coaching council (EMCC) has a code of ethics which mentors could subscribe to. ${ }^{19}$ Training per se is not shown to lead to mentorship quality but training that is perceived as high quality and of some duration is shown to relate positively especially to the psychosocial aspects of mentoring. ${ }^{20}$ The average duration of training is about five hours contrasting to some training schemes for medical mentors which can be up to three days with regular updates. It has been suggested that though training for mentor and mentee is important it is more so for the mentor, otherwise the mentoring relationship is more likely to be unsuccessful. ${ }^{21}$

What is good about the relationship is that the mentor is approachable, supportive honest and trustworthy. The mentees found empathy in these situations and the feeling of not being alone. They found the space for reflection which is essential to personal and professional development. The relationship was a safe place for those difficult but essential questions to be asked, allowing growth.

Some mentees also see their mentors as role models they see something in them they want to aspire to or learn from, this is one of the recognised roles of a mentor. Nonmentored trainees have similar views but also add that it is an opportunity to network. This could be a way of succession planning though if exclusive, would give the impression of patronage which is certainly frowned upon as it is

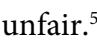

In a study mentored employees had the perception of more power, especially if the mentor is highly placed and if 
they are male mentees. ${ }^{22}$ Mentees were more satisfied with their mentoring relationships when there were set goals and objectives and if they have input in the matching process, this improved the satisfaction with their mentor. ${ }^{23}$ Mentoring is especially helpful in a situation of 'being stuck'. The mentor acts as a sounding board which enables a can do attitude, inspiring confidence to achieve and help with interpersonal skills. Academic trainees in particular said they would not have achieved what they had without a mentor, it is essential.

Constructive and impartial advice was also received as well as emotional and moral support. The Socratic method of enquiry of series of questions which eventually leads to a conclusion can be helpful in these situations. ${ }^{24}$ Mentoring helps with the development of empathy for others. Mentors help with the understanding of difficult and troubling experiences. They inspire, eliminate blind spots and even change lives. ${ }^{25}$

\section{When mentoring goes wrong}

Mentoring sometimes goes wrong; these issues were reviewed. ${ }^{11}$ The assigning of a mentor to a mentee is thought to be a problem in formal mentoring systems as the mentee has no choice, and they may not necessarily get on. Dependency may develop and confidences betrayed leading to detrimental effect on careers. ${ }^{11}$ Mentees can feel annoyance at the mentors for not providing adequate time for them and mentors may feel that the mentee is not appreciative of their time and effort. This was the perception that some of the mentees had about mentoring that goes wrong. This perhaps could be mitigated by the selection of mentors who have undergone some training. Five causes of poor relationship between mentor and mentee were identified. Mismatch in expectations; impression management tactics; incompatible personal styles; incompatible career stages and career anchors of mentors and mentees; role conflicts for mentors. Mentoring is working when the mentees say they are satisfied with their mentoring relationships. The problems encountered have been when the mentor says that the mentee has to do what they have prescribed rather than the mentee finding a solution with the support of the mentor as a sounding board. This potentially can be addressed by the training of mentors. These findings raise the question of whether mentoring relationships should be evaluated to better understand more about how a relationship is developing, when it has gone beyond its useful purpose, whether it is achieving its aim and how can such relationships be better developed.

A main hindrance was the lack of time and knowledge of mentoring and potential benefits, especially in busy practices. Educational supervisors could perform the mentoring role but not for their trainees and would likely require additional training in this new role. There was also a lack of perceived opportunity and availability especially for less than full time trainees and new trainees to a deanery.
Ethical issues include abuses in the relationship, manipulative behaviour, revenge and some mentors have reported back stabbing behaviour. There have also been reports of mentoring being exclusionary, excluding people of colour and women. Others say that it re-enforces the current state of affairs with regard to power and conflict. A survey reported that up to $54 \%$ of mentees have experienced a dysfunctional mentoring relationship the common reasons were differences in work style, values and personality. Seven mentoring obligations are identified; beneficence, nonmalficience, confidentiality, autonomy, fairness, loyalty and concern. ${ }^{10}$

\section{Potential implications for health care organisations and medical education}

Initiative brought by all these mentored trainees, consultants and general practitioners of the future would be impressive, impacting on the culture of medicine towards a more supportive one. The organisational context of mentoring is important, as in industry; senior male mentors are levers of power in networks that mentees might not have access to. ${ }^{26}$ The concept of the signalling theory, which states that, the association of a respected senior person signals the worthiness of the individual to the organisation would be relevant. ${ }^{27}$ Female mentors may not perceive or be perceived to have similar powers as male mentors, and organisational structures are more favourable to men. ${ }^{26}$

The issue of someone in an assessment role like the educational supervisor also being the mentor for the same individual raises the problem of a conflict of interest as an unbiased and objective assessment may be difficult. This is an important implication for medical education and needs more study as a number of non-mentored trainees and mentees have raised this point. Educational supervisors being mentees for other trainees and indeed senior trainees mentoring more junior trainees would be a way forward. It would increase the pool of trainees and foster a more supportive culture with a rounded and effective doctor at the end of training which can only be a good thing for patient care.

The limitations of this study include, this study being a pilot with a cross-sectional sample. A number of the issues studied would need to be revisited in a longitudinal study which was not feasible because of the time constraints. Triangulation of the findings would have helped with the validity of the study, although limited by the confidential nature of the study. The generalisability of this study may be limited because this is a study of a specific group in the health sector.

\section{Conclusion}

Mentoring on the whole makes a positive contribution to the personal and professional development of the individual. There needs to be a diversity of mentors to cater for the diverse needs of the trainees. Educational supervisors are 
valued in their role as supervising the adherence to the curriculum. However the need for mentors who assist the trainees in overseeing their professional and personal commitments is stressed by all the trainees as a valuable resource which they would like access to, for all. The separation of mentoring and educational supervision as two distinct roles is also important and relevant to medical education. Future studies looking at dysfunctional mentoring in medicine, the role of evaluation in helping to understand and develop the mentoring relationship and to ensure that its role as a means of giving individuals opportunity to grow and flourish is preserved.

\section{Conflict of Interest}

The authors declare that they have no conflict of interest

\section{References}

1. Collin A. Learning and development. In: Beardwell I, Holden L, Claydon T, editors. Human resource management: a contemporary approach.4th ed. Harlow: Pearson Education Limited; 2004. p.266-309.

2. Gormley B, Lingam S, Gupta R. Coaching in Medicine. Liverpool: Mersey Deanery (University of Liverpool/NHSE); 2004.

3. British Medical Association. Exploring mentoring. Board of Medical Education. London: British Medical Association; 2004.

4. General Medical Council. Leadership and management for all doctors. Manchester: General Medical Council; 2012.

5. Collins EGC, Scott P. Everyone who makes it has a mentor. Harvard Business Review.1978;56(4): 89-110.

6. Kram KE. Mentoring at work: developmental relationships in organizational life. Glenview, IL: Scott, Foresman;1985.

7. Meldrum $\mathrm{H}$. Who inspired the most inspiring doctors? The International Journal of Clinical Leadership; 2011;17: 31-5.

8. Baugh SG, Fagenson-Eland EA. Boundaryless mentoring: an exploratory study of the functions provided by internal versus external mentors. Journal of Applied Sociology Psychology: 2005;35(5): 939-955.

9. Bould J. Mentoring in medicine: The practical guide. Leeds: CCDU Training and Consultancy. 1996: p3-4.

10. Moberg DJ, Velasquez, M. The ethics of Mentoring. Business Ethics Quarterly.2004;14(1): 95-122.
11. Feldman DC. Toxic mentors or toxic proteges? A critical re-examination of dysfunctional mentoring. Human Resource Management Review. 1999; 9(3): $247-278$

12. Liu Y, Xu J, Weitz BA. The role of emotional expression and mentoring in internship learning. Academy of Management Learning and Education 2011;10: 94-110.

13. Straus SE, Chatur F, Taylor M. Issues in the mentor-mentee relationship in academic medicine: a qualitative study. Academic Medicine 2009;84:1359.

14. Schilling J. On the pragmatics of qualitative assessment: designing the process of content analysis. European Journal of Psychological Assessment; 2006; 22: 28-37.

15. Braun V, Clarke V. Using thematic analysis in psychology. Qualitative Research in Psychology. 2006; 3: 77-101.

16. Gupta RC, Lingam S. Mentoring for doctors and dentists. Oxford: Blackwell Science Ltd; 2000.

17. Clutterbuck D. Everyone needs a mentor: fostering talent in your organisation.4th ed. London: Chartered Institute of Personnel development. 2004.

18. Ragins BR, Cotton JL, Miller JS. Marginal mentoring: the effects of type of mentor, quality of relationship, and program design on work and career attitudes. Academy of Management Journal. 2000; 43:1177-1194.

19. European Mentoring and Coaching Council [Internet]. Marlborough: code of ethics; 2008 [cited 2012 Nov 1]; Available from: http://www.emccouncil.org/.

20. Allen TD, Lentz E, Eby LT. Mentorship behaviors and mentorship quality associated with formal mentoring programs: closing the gap between research and practice. Journal of Applied Psychology. 2006;91:567-578.

21. Gray WA. Developing a planned mentoring program to facilitate career development. Career Planning and Adult Development Journal. 1988;4:916.

22. Fagenson EA. The power of a mentor. Group and Organizational Studies.1988;13(2): 182-194.

23. Viator RE. An analysis of formal mentoring programs and perceived barriers to obtaining a mentor at large public accounting firms. Accounting Horizons.1999;13:37-53.

24. Areeda PE. The socratic method: lecture at the Puget Sound. Harvard Law Review. 1990;109: 911-922.

25. Lazarus A. Achieving success through mentors. The Physician Executive Journal of Medical Management.2012; 38(1):42-46

26. Ramaswami A, Dreher GF, Bretz R, Wiethoff C. Gender, Mentoring, and career success: the importance of organizational context. Personnel Psychology. 2010; 63:385-405.

27. Spence M. Job market signalling. Quarterly Journal of Economics.1973; 87: 355-374.

\footnotetext{
Appendix

Questions asked of those without a mentor

- Have you ever had a mentor?

- What do you think mentoring is?

- Is it a good thing to have a mentor?

- What is good about having a mentor?

- What is bad about having a mentor?

- What would you expect in the mentoring relationship?

- Should mentoring be an important part of training? If yes then 8

- In what way should mentoring be an important part of training?

- What characteristics make a good mentor?

- Were there any barriers or facilitators to identifying a mentor?

- Does gender play a role in the mentor/mentee relationship?

- Should the mentor and mentee be of the same gender?

- Any further comments you would like to make?

Questions asked of those with a mentor

- Have you ever had a mentor?

- What do you think mentoring is?

- How did you start the mentoring relationship?
}

- What did you expect in the mentoring relationship?

- What did you get in the mentoring relationship?

- Where you satisfied or dissatisfied with the mentoring relationship?

- What happened in the process?

- What was good about the mentoring relationship?

- What could have been improved about the mentoring relationship?

- Did you feel it was important for you? If yes then 10

- In what way was it important for you?

- Should mentoring be an important part of training? If yes then 12

- In what way should mentoring be an important part of training?

- How has mentoring helped your career?

- How has mentoring hindered your career?

- What characteristics make a good mentor?

- Is the person internal or external to the organisation?

- How many do you have?

- Were there any barriers or facilitators to identifying a mentor?

- 20) Does gender play a role in the mentor/mentee relationship? Should the mentor and mentee be of the same gender?

- Any further comments you would like to make? 